\title{
Las ideas fundadoras de la Universidad Ricardo Palma
}

\author{
Jaime Ríos Burga \\ Universidad Ricardo Palma \\ jaimecultural @gmail.com
}

A los fundadores y colegas de la URP

Un maestro -o, mejor, un catedrático - en quien sus discipulos descubren una magra corteza de cultura profesional, y nada más, carece de autoridad y de aptitud para inculcarles y enseñarles extensión ni hondura en el estudio.

Mariátegui, estudiantes y maestros, 1928

\section{RESUMEN}

El presente ensayo aborda y reconstruye el curso de las ideas fundacionales de la Universidad Ricardo Palma, desde su imaginario y diferentes etapas de construcción, reforma institucional y sus desafíos de futuro. Un modelo de universidad basado en la universalidad del conocimiento, como una forma de democracia en acción por hacer de los humanos más libres, iguales, solidarios y diferentes. Fundada en una nueva cultura civilizatoria que supera todo pragmatismo.

Palabras clave: Universidad Ricardo Palma, pensamiento fundacional, paradigma, reforma institucional, modelo de universidad.

\section{The founding ideas of Ricardo Palma University}

\begin{abstract}
This essay addresses and reconstructs the course of ideas that led to the founding of the Ricardo Palma University, from its inception through its different stages of construction, its institutional reform and future challenges. A university model based on the universality of knowledge, as a form of democracy with the aim of making humans more free, equal, caring and different beings. Founded on the basis of a new civil culture that surpasses all pragmatism.
\end{abstract}

KeYwords: Ricardo Palma University, foundational thinking, paradigm, institutional reform, university model. 


\section{Las herencias de pensamiento fundacional}

La Universidad Ricardo Palma (URP) nace bajo el espíritu humanista, poético y literario de Ricardo Palma (Rodríguez, 2003), es decir el legado de los pensadores forjadores de la universidad en el Perú (Rodríguez, 2009). Como destacara en su tiempo José Carlos Mariátegui recoge históricamente la influencia de la herencia española, la influencia francesa y norteamericana (Ríos, Vol. III, 2008; Ríos, Vol. I, 2009). Espíritu humanista creativo que asume la vitalidad creativa de Palma quien lo expresa en su propia biografía editada en Barcelona: Las mejores Tradiciones peruanas:

Amorcillos de estudiante me obligaron a dejar la Universidad y aprovechando mi nombramiento de oficial del cuerpo político, me embarqué como Contador en nuestra armada. En una larga estación en las Islas de Chincha, me leí la Biblioteca de Clásicos de Rivadeneira: de ahí mi devoción por los grandes prosistas castellanos. Naufragué en el Rímac, el 55. Gran partidario de don José Gálvez tomé parte en el asalto de la casa de Castilla. Salí desterrado a Chile. San Román me nombró Cónsul en Pará y viajé a Europa y Estados Unidos. A mi regreso entré en la revolución contra Pezet. Trabajaba en Ministerio de Guerra con don José Gálvez y no volé en el torreón de La Merced porque Gálvez me envió en comisión al telégrafo. Entré en revolución a favor de Balta y fui Secretario Privado y Senador por Loreto, hasta la administración de Pardo. En 1872 me casé y me retiré de la política activa. Cuando la guerra, vivía en Miraflores, me batí en los reductos y los chilenos me quemaron, sin abrirla, la casa y mi biblioteca personal bastante valiosa. Durante la ocupación viví de mis correspondencias a periódicos extranjeros, especialmente a La Prensa de Buenos Aires. Paz me hizo proposiciones muy ventajosas para que me trasladara a Buenos Aires como redactor de su periódico; acepté; Iglesias y Lavalle me hicieron caer en la tentación de reconstruir la Biblioteca; si los hubiera desairado, no sería hoy pobre de solemnidad. En 1892 fui a Espańa como representante del Perú para el Cuarto Centenario del Descubrimiento de América; los literatos espańoles me colmaron de halagos. En 1912 renuncié a la Dirección de la Biblioteca Nacional por no transigir con imposiciones desdorosas del Presidente Leguía. Merecí grandes manifestaciones de desagravio. Dejé la casa donde habité veintiocho años, donde nacieron varios de mis hijos y donde murió mi mujer; y me vine a este pueblo (Miraflores) de donde no saldré ya. Distraen mi soledad algunos amigos y las visitas de los extranjeros que, al pasar por Lima, tienen curiosidad por conocerme. Lo Último que he escrito por compromiso ineludible con La Prensa de Buenos Aires se titula «Una visita al Mariscal Santa Cruz». Se publicó en el número del 10 de enero de 1915 (Palma, 2008).

Pero, la URP hereda también el espíritu de la reforma universitaria de Córdova que proclamaba que «estamos pisando sobre una revolución, estamos viviendo una hora 
americana» (Ríos, J. 2009) y de la reforma universitaria de San Marcos que ha contribuido siempre a la formación de la nacionalidad (Maticorena, 2009). Busca cumplir con la promesa de la vida peruana de la generación del Comité de la Reforma Universitaria bajo la dirección de Víctor Raúl Haya de la Torre, quienes en su Manifiesto a los Jóvenes Universitarios del Perú se preguntaban con razón y fe: ¿¿Por qué actuamos?, ¿qué perseguimos?, ¿qué es nuestra Universidad?, ¿`cuáles han sido nuestras demandas y cuál es nuestra Universidad del futuro? Proclamaban en relación a la primera interrogante:

Perseguimos la organización nacional por medio de la cultura nacional. Queremos descolonizarnos un tanto de las metrópolis científicas europeas; aspiramos al conocimiento de nuestro mundo por nuestro propio esfuerzo intelectual; tratamos de acabar con la disociadora aristocracia universal, infiltrando la ciencia que democratiza y unifica: deseamos curarnos de las nocivas abstracciones y del extranjerismo ideológico, desviado y enervante; anhelamos formar nuestro criterio positivo para el análisis de este enfermo yaciente que se llama «Perú (Basadre, 1975).

Ideología y reivindicación que surge como parte del movimiento democrático nacional planteando nuestra independencia científico cultural como peruanidad universal frente al control y dominio colonial del saber y del poder de los Estados-nación potencia occidentales, de sus oligarquías y clientela. Postulados esenciales que expresaban el cambio radical de esta estructura de dominación y control económico, social, político y cultural apostando por la autonomía y la democratización de la sociedad y la universidad peruana. Una lucha por la hegemonía científico cultural que enfrentó a los intelectuales civilistas y los intelectuales de la reforma democrática bajo dos espíritus: la feudalidad y el capitalismo (Mariátegui, 1972).

Corresponde también destacar que la URP nace bajo la influencia del pensamiento de José Carlos Mariátegui quien planteaba que el problema educativo y universitario en el Perú en su verdadero término y sentido era económico social y que en nuestro caso producía y reproducía culturalmente su dominación. Pero también de las ideas de Víctor Raúl Haya de la Torre en sus ideas antiimperialista y libertarias porque como escribiera: «Empero, la reforma, como la independencia americana de Espańa, se mueve influida por nuevos movimientos en Europa, por contemporáneas crisis profundas, crisis de decadencia del orden capitalista, del liberalismo burgués sangrientamente establecido por la gran revolución francesa. Europa, siempre más adelante, nos influye y otra vez nos influye imprecisamente produciendo en nosotros nuevas paradojas» (Haya, 2009).

Construir una cultura nacional que transforme la mentalidad de la aristocracia y la burguesía criolla oligárquica, pues reproducían imitativamente la vida del dominador en todo un complejo de mentalidad e ideología no permitiendo el acceso a la educa- 
ción a la clase media y sectores populares. Movimiento socio político que en la década del sesenta y setenta del siglo xx se radicaliza en permanente cuestionamiento contra a herencia de los malos métodos y malos profesores porque tomaron conciencia que "el problema de la universidad no está fuera del problema general de la enseńanza» (Mariátegui, 1973).

La universidad tenía que cambiar porque como señalaba Mariátegui en su conocido artículo: «La crisis universitaria, crisis de maestros y crisis de ideas»: «Un maestro, uno no más, bastaría para salvar a la Universidad de San Marcos, para purificar y renovar su ambiente enrarecido, morboso e infecundo. Las bíblicas ciudades pecadoras se perdieron por carencia de cinco hombres justos. La Universidad de San Marcos se pierde por carencia de un maestro... Y esta es la crisis de la Universidad. Crisis de maestros y crisis de idea. Una reforma limitada a acabar con las listas o a extirpar un profesor inepto o estúpido, sería una reforma superficial. Las raíces del mal quedarían vivas. Y pronto renacería este descontento, esta agitación, este afán de corrección, que toca epidérmicamente el problema sin desflorarlo y sin penetrarlo» (Mariátegui, 1973).

Los fundadores de la universidad Ricardo Palma surgen en lucha contra este pensamiento conservador oligárquico de élite y casta planteando que la universidad expresa la ecuación: Universidad = Mística + Imaginación + trabajo (Ludeña, 1994). Continua con el espíritu de la reforma universitaria que «bajo tal nombre se reconoce un intenso y vasto movimiento de insatisfacción juvenil encaminado a romper las trabas de antiguos sistemas de enseńanza y vida en la universidad y de las relaciones entre ésta y la ciudadanía en general. Quien pretenda reducir la Reforma Universitaria a los meros ámbitos de la universidad cometería un grueso error. Siendo la universidad en América Latina, espejo fiel de la existencia colectiva» (Sánchez, 2009). En este sentido había en parte replantearse lo que planteaba Basadre cuando señalaba que deben colaborar «en el cumplimiento de la misión de la Universidad, el cuerpo docente o profesional, el cuerpo discente o escolar, el cuerpo circunviviente, esto es la sociedad, y el cuerpo regente, o el Estado» (Basadre, 2010). Surgen así otras universidades privadas en el Perú.

Los fundadores de la URP recogieron así mismo el espíritu de crítica radical al intelectualismo bajo la idea de transformar la realidad socioeducativa existente. Buscaron en los hechos contribuir a organizar mejor la vida del país de manera práctica superando la herencia de la promoción arialista (Sánchez, 1968) y de la propia reforma universitaria. Pues, ante el débil liberalismo, debemos tener nuestra propia capacidad creadora asumiendo el papel y la responsabilidad de pensar por sí mismos los problemas, construirnos como actores de una peruanidad universal.

En esta línea de pensamiento se trataba de refundar la sociedad y la universidad transformando el desarrollo de la razón instrumental, el rol del conocimiento científico y tecnológico, la construcción de la nación, como superación del fraccionamiento feudal. Es decir, como anotaba Gerardo Ramos «el más grande desafío que tenemos que 
afrontar como productos alienados de una sociedad alienada. Debemos empinarnos sobre nosotros mismos y proponer a nuestros pueblos alternativas de vida buena y desmitificar el eurocentrismo y rechazar el espejismo de que nuestra salvación está en imitar compulsivamente a los países superindustrializados» (Ramos, 1999).

Una cultura como proyecto nacional de peruanidad donde lo humano se exprese realmente en un movimiento histórico cultural en igualdad, libertad, solidaridad y felicidad como realidad peruana universal. Propuesta que en sus diferentes vertientes ideopolíticas toma cuerpo en nuestra América en el ideal de «quereremos descolonizarnos». Como decía Octavio Paz no podemos tener una visión creativa de futuro sino partimos del análisis del capitalismo contemporáneo y su razón cultural nihilista porque como escribiera en Tiempo Nublado: «(...) el verdadero mal de las sociedades capitalistas liberales no está en ellos sino en el nihilismo predominante. Es un nihilismo opuesto al de Nietszche: no estamos ante la negación crítica de los valores establecidos sino ante su disolución en una indiferencia pasiva» (Paz, 1986).

\section{Construcción y reforma institucional}

Gerardo Ramos, Rector fundador de la URP, en una entrevista destacaba con razón que «la universidad peruana, una de las primeras de América, surge al interior de un proyecto de expansión mundial de la cultura occidental, en su versión hispana. Con esto quiero decir que los contenidos y las formas de la educación que se forjan y desarrollan en la universidad peruana tendrán mucho que ver con la racionalidad con la que los españoles manejaban la sociedad, la economía, la política y la ciencia» (Ramos, 1999). Razón colonial que debemos superar pensando nosotros por sí mismos y no bajo una racionalidad de poder y dominación:

Es innegable - escribe- que la occidentalización fue un hecho guerrero por excelencia, pero habría que añadir el hecho que Europa hace del conocimiento un elemento esencial de concentración del poder. Para Bacon saber era poder. Es pues una racionalidad instrumental, que asocia el poder al saber, la que señala cómo dominar el mundo, la naturaleza, las sociedades... (Ramos, 1999).

En un conflicto inter civilizatorio que desde la occidentalización como lógica de poder busca homogenizar y controlar la vida social. Gerardo Ramos se preguntaba:

¿Por qué la «realimentación» de tan importantes factores de la tradición greco-romana fue buena para la construcción de «la» modernidad, mientras que las tradiciones del 
Mundo Andino son peligrosas y hasta vergonzosas y opuestas a la creación endógena de una nueva modernidad en estos mundos? ¡Caprichos del eurocentrismo!

Paradójicamente, en la «utopía arcaica» Vargas Llosa sostiene que nuestro atraso nos viene de nuestra herencia indígena, y que el único desarrollo posible consiste en imitar a los países más industrializados. Obviamente eso no es cierto. Y he allí un reto para nuestra educación universitaria: recrear el país, en contra de esa dominante actitud eurocentrista que se reproduce cotidianamente en ideologías y prácticas sociales perversas (Ramos, 1999).

Un pensamiento que busca desentrañar las causas de nuestra dependencia pero también de nuestras problemáticas históricas internas y plantear una salida desde nuestra propia especificidad diversa, pues la racionalidad económica occidental hegemónica lleva a la unidimensionalidad de la vida. Escribía:

Personalmente, no creo ni afirmo que la sociedad occidental o los individuos que la componen sean unidimensionales, sino que las fuerzas económicas empujan a la sociedad hacia la adopción de una unidimensionalidad absoluta tal que, si el modelo de «desarrollo» lo exige, hay que destruir a los seres portadores de distintas opciones culturales. Esto explica los genocidios de los indígenas norteamericanos, centroamericanos, andinos y africanos y la destrucción de las culturas, de las religiones, de las lenguas y de todos los vestigios que pudieran recordar sus tendencias anteriores, practicándose un gigantesco etnocidio.

El proyecto de Occidente se habrá cumplido con todo éxito cuando los pueblos dominados no solamente acepten la unidimensionalidad económica, determinada por el mercado y el consumismo, sino cuando la promuevan como un valor, y aspiren a ella con todas sus esperanzas. Entonces habrá llegado «el fin de la historia», en cuyo umbral algunos de sus profetas anuncian que ya estamos (Ramos, 1999).

Por lo tanto había que sacar a luz nuestra situación de problemáticas, principalmente de control y dominación para buscar nuestra propia modernización nacional. Vemos como aquí en los fundadores de la URP están presentes los ideales de la Reforma Universitaria:

¿Cómo afectó y sigue afectando a las culturas andinas la agresión por parte de la racionalidad occidental?

A la llegada de los españoles los pueblos andinos habían logrado ya, en base al manejo exitoso de los diversos pisos ecológicos y a la complementariedad pan andina, convertir el suelo árido y los amenazantes bosques y laderas de escasos recursos en los que 
vivieron sus antepasados en un paisaje dócil, hermoso, y proveedor de recursos para alrededor de diez millones de habitantes.

En gran parte de la historia de la humanidad, el factor humano ha sido instrumentalizado a su acción productora, como «recurso humano». Desde esa opción, y en el contexto de la hegemonía de los países industrializados ¿cuáles son los horizontes posibles para los pueblos del Perú?

Considero que no hay salida posible si no nos elevamos sobre la cosificación del ser humano por la cual éste es, fundamentalmente, animal de carga o de cultivo, es productor y reproductor de fuerza de trabajo, es siervo dócil, es máquina inteligente, es máquina peligrosa cuando pierde la paciencia y reclama sus derechos... Es obvio que hay una doble moral que al mismo tiempo que se cosifica al ser humano se lo considera como un todo inmensamente perfeccionado y perfeccionable, dotado de voluntad, de creatividad y del sentido de los valores (Ramos, 1999).

Ideal recurrente también en el planteamiento de construir un proyecto de sociedad política que se asiente en nuestra rica historia civilizatoria:

Efectivamente, yo señalé entonces que un proyecto histórico para el Perú debe dar alternativas no solo a la modos y formas de producir y distribuir la riqueza, sino también debe reflejar las características más importantes de nuestra estructura social: la coexistencia de los muchos pueblos de distintos orígenes (quechuas, aymaras, más de 50 grupos amazónicos, así como a descendientes de africanos, asiáticos, europeos). No es posible reducir el ordenamiento social al sólo eje económico, pues frente al dato de la posición económica puede exhibirse también un número de ciatos fundamentales que diferencian a las personas: etnia de origen, concepción del mundo, religión, cultura, etc.

Con el propósito de ensayar un modelo bidimensional para la sociedad peruana, se tiene que subrayar que conjuntamente a la estratificación social, las etnias peruanas deben ser consideradas como sujetos históricos en un proyecto de país pluricultural y multiétnico (Ramos, 1999).

Discurso que entra en debate y diferencia con la filosofía y ciencia de occidente. Lo que se trata es de construir planificadamente un proyecto societal que una a los peruanos con su historia, la naturaleza y vida social como sociedad organizada sobre la base de la descentralización. Al respecto reflexiona en los siguientes términos:

¿Discutimos sobre Vico, Habermas y Lyotard, sin hablar nada de los ashánincas?

Algo parecido a ello. Aunque ya esta posición, por sí sola, representa un avance frente al desolador panorama que vivíamos hace poco aplastados por el discurso economicista 
de la modernidad occidental (ya sea en su versión capitalista o en su versión socialista), en donde «civilizar» era la palabra clave, no obstante que en Perú, como en toda América, civilizar — en la práctica — ha significado siempre desindianizar, imponer la cultura occidental. No olvidarnos todavía que el camino más corto hacia la civilización para argentinos y chilenos fue el genocidio de los indígenas, y que para otros, el camino era «blanquear» la población indígena con la inmigración europea. Es contra esta mística unidimensionalizante, que la parte del Perú criolla y occidental ha desarrollado en detrimento de la solidaridad de los seres humanos y de sus culturas, que lo mejor de la intelectualidad peruana — que saldrá de sus universidades — tiene que forjar proyectos alternativos.

Resumo. La educación en sí misma no es la solución a todos los problemas, pero es una de las mejores herramientas que tenemos para salir del actual estado de cosas, Arcadio Buendía no se equivocaba cuando al fundar Macondo lo primero que hizo fue separar un sitio para la educación de la gente» (Ramos, 1999).

En otras o palabras:

Considero que la premisa esencial, que se desprende de mis intervenciones anteriores, es que la sociedad peruana en su conjunto, y la universidad dentro de ella, tienen que volver los ojos hacia nuestra naturaleza y nuestra historia; es decir alentar la educación ambiental, la historia regional y en esos contextos recrear el conocimiento y las tecnologías universales. Pero ello implica, entre otras cosas, asumir los siguientes desafíos:

Reconocimiento de las posibilidades de nuestros ecosistemas y de su biota, que es tarea de la ciencia, y la optimización de sus usos mediante una utilización razonable del conocimiento universal, en el que incluyo, por supuesto, el legado de conocimientos de las culturas andinas. En esa línea, habrá que alentar los procesos autónomos de creación de tecnología y la reconstrucción de una relación sana con la naturaleza promoviendo los atributos genuinos de generación de riqueza entre los que destacan el aumento de la diversidad biológica.

Todo esto tendrá su correlato en el desarrollo de la industria complementaria en función de las aspiraciones sociales y el respeto a la naturaleza, y en la utilización de tecnología biológica avanzada para exportar productos de alto valor agregado que permita cubrir un adecuado stock de divisas.

Debo añadir que en la base de esas líneas de acción deberá estar la organización de una sociedad descentralizada de productores que sea estable en la medida en que se respeten los ecosistemas, los derechos de cada región y las aspiraciones étnicas y económicas legítimas (Ramos, 1999). 
Las condiciones del capitalismo global exigían que la URP se adecue a sus nuevas dinámicas. Corresponde aquí un papel central de gestor y organizador al rector Iván Rodríguez Chávez quien consolida su vida institucional partiendo de la defensa del ideal central de la Reforma Universitaria: la autonomía. Al respecto escribe:

La autonomía universitaria tenemos que pensarla como un atributo de la universidad; es decir como una propiedad esencial e infaltable de la universidad, al punto que procede afirmar categóricamente que no podemos concebir universidad sin autonomía ni aquí ni en ningún otro sitio, ni antes, ni ahora, ni en el futuro. La modernidad tendrá consecuencias parciales en la organización y funcionamiento de la universidad, pero nunca afectará su autonomía, menos la debilitará; muy por el contrario, los tiempos contemporáneos ratificarán y reforzarán la autonomía en tanto elemento indispensable que garantiza a la universidad el logro de sus fines y el cumplimiento cabal de sus funciones (Kapsoli, 1999 o Rodríguez, 2010).

Defensa que viene de su formación crítica humanista en su Alma Mater: la UNMSM. Nos recuerda al respecto:

Admitiendo que cada profesor mencionado y también de los no mencionados ha contribuido en mi formación, cábeme declarar que la columna vertebral de esta, con influencia en mi época de estudiante y en mi vida profesional posterior fue el doctor José Jiménez Borja, profesor de metodología del castellano y la literatura y de castellano avanzado ii. si hubiera sido delgado se le hubiera visto más alto. Más que grueso, su cuerpo se ubicaba en el campo de una gordura mediana. de frente, su cara parecía reposar sobre su pecho. Coronaba su figura, una calvicie estacionada a mitad de camino. su paso sosegado, su hablar lento con vocales alargadas, le imprimía una majestad reverente. En todo momento irradiaba una serenidad que indicaba que todo lo que hacía cabía en su tiempo. En los años que lo traté nunca lo vi apurado. Se había apropiado de una tranquilidad resignada como que la vida le daba plazo para realizar sus sueńos. Sus clases comenzaban puntualmente a las ocho de la mańana. Ingresaba en el aula, pausado y sonriente. Los alumnos, en aquellos tiempos reverenciábamos al profesor poniéndonos de pie cuando entraba y cuando salía. Como pocos, usaba la lista para registrar la participación de los alumnos en clase. Era habitual el silencio y la avidez con que se le escuchaba. En sus disertaciones usaba sincronizadamente la elocución y la pizarra. En todo momento exhibía solidez conceptual que manejaba con seguridad, pero sin pedantería .se le quería y respetaba por su saber y se le temía por su exigencia. era uno de los profesores fundadores de la facultad de educación. En letras, había sido profesor de muchos docentes e intelectuales de figuración por esa época. su prestigio de gran conocedor del idioma lo había encumbrado a la secretaría perpetua 
de la academia peruana de la lengua, de la cual fue posteriormente su director. en su actividad docente era justo, pero riguroso. Las dificultades en el aprendizaje sólo se salvaban con el estudio y el esfuerzo. Era acogedor y fraterno. Estimulaba al estudioso y daba oportunidades de desarrollo. Sus clases en ambos cursos, se distinguían por su orden, claridad u dosificación. a la teoría la respaldaba con ejemplos que se analizaban adecuadamente. Había tal exigencia, que para llevar su curso tenía que enfrentar a tina evaluación previa que no todos aprobaban. Para obtener el calificativo promocional era requisito grabar textos poéticos acreditando la clara pronunciación de la elle, de la ese y de los otros sonidos de uso fonético relajado. Los exámenes escritos eran prácticamente individualizados. Concurría al aula con las preguntas formuladas por escrito, a máquina, en papeles pequeños que nos iba entregando uno a uno, de acuerdo con la lista. Por las medidas que adoptaba era imposible el soplo o el plagio. En las clases modelo, el examinado debía demostrar aplomo, seguridad, conocimiento, buen uso de la pizarra, ingenio creativo e impecable vocalización y pronunciación. Cualquier error o desconocimiento era imperdonable. Jiménez Borja pensaba que el profesor de castellano tenía que estar idóneamente formado para garantizar una adecuada enseñanza. Su función lo conminaba a ser un modelo de uso idiomático. Con el correr del tiempo, todos los que hemos sido sus alumnos le agradecemos sus enseñanzas y le damos plenamente la razón (Kapsoli, 1999 o Rodríguez, 2010)

Formación crítica que con toda la experiencia se integra a su esfuerzo creativo por hacer de la URP un centro creativo con autonomía (Chávez, 2010) al servicio de la sociedad peruana. Decía al ser elegido Rector de la Universidad:

El 26 de noviembre de 1996, de entre tres candidatos, fui elegido rector de la Universidad. Llegué al cargo como desarrollo natural de los acontecimientos especiales por los que atravesaba la universidad. Ellos, cada vez más, me fueron comprometiendo con la administración. Para aceptarlo pesó mi vocación magisterial y mi cariño por la universidad. Desde estudiante en la cuatricentenaria San Marcos, aprendí a amarla y a apreciarla como el único espacio social donde podía realizar mis aspiraciones intelectuales. Como profesor la vi siempre más allá de un simple centro de trabajo. Además, de las indagaciones por las asignaturas a mi cargo, siempre me interesó conocerla en su historia, en su estructura, en su funcionamiento y en su conexión con la sociedad. Ser elegido rector honra, pero es mucho más un compromiso. Importa la concepción que sobre este cargo tenga la persona. Siendo un timbre de adorno individual su trascendencia social es mayor. En mi caso accedí convencido que el rectorado es una función de servicio; que uno entra a servir a la sociedad a través de la Universidad. Y, por esta estrecha relación entre sociedad y universidad, también es saludable poseer una concepción de universidad. Desde antes de mi elección, ando persuadido que la 
Universidad es una institución de servicio político, independientemente sea esta estatal o privada. A tales ideas-fuerza concurren las buenas intenciones, la buena fe la seguridad que un cargo no cambia a la persona.

Debo confesar que no pertenezco a partido político ni grupo social de poder. Soy profesor y abogado que ama la docencia, Desde que concluí mis estudios profesionales, sumo treinta años de dedicación al magisterio subvencionados por los honorarios percibidos como abogado (Kapsoli, 1999 o Rodríguez, 2010)

Pero, esta labor tiene su impacto producto de la actitud y conocimiento profundo de la vida universitaria. Escribe:

Ser elegido rector honra, pero es mucho más un compromiso. Importa la concepción que sobre este cargo tenga la persona. Siendo un timbre de adorno individual su trascendencia social es mayor. En mi caso accedí convencido que el rectorado es una función de servicio; que uno entra a servir a la sociedad a través de la Universidad. Y, por esta estrecha relación entre sociedad y universidad, también es saludable poseer una concepción de universidad. Desde antes de mi elección, ando persuadido que la Universidad es una institución de servicio político, independientemente sea ésta estatal o privada. A tales ideas-fuerza concurren las buenas intenciones, la buena fe la seguridad que un cargo no cambia a la persona.

Debo confesar que no pertenezco a partido político ni grupo social de poder. Soy profesor y abogado que ama la docencia, Desde que concluí mis estudios profesionales, sumo treinta años de dedicación al magisterio subvencionados por los honorarios percibidos como abogado (Kapsoli, 1999 o Rodríguez, 2010)

Una veta de esfuerzo corresponde hacer que la universidad peruana universalice lo humano al servicio de la vida. Escribe:

Como toda obra humana, los adelantos electrónicos han mejorado en algo las condiciones de vida. Como costo de este regalo, viene enterrando sentimientos, ilusiones y romanticismos. El laboratorio líquida a la cigüeña que nos trajo a nosotros. Ahora los niños no vienen por encargo. La madre a los tres meses ya conoce del sexo con el que la naturaleza ha prodigado a su hijo.

Los inventos del hombre honran su inteligencia. Creando nuevos mundos artificializan la vida. El confort que halaga víctima y beneficia. Da vida y quita vida. El estrés es el precio más caro que factura bienestar material a costa del vigor del espíritu.

Ante este panorama ¿qué le cabe a la universidad?, ¿qué le incumbe a un rector? Personalmente pienso que mucho. A la universidad le corresponde trabajar en el hombre: formarlo, educarlo; hacer de cada individuo un verdadero hombre. La gran tarea 
del futuro sería de proveerle al hombre lo que la civilización electrónica y monetaria le mezquina: Amor, justicia, igualdad. La universidad le pondrá la pierna de espiritualidad para que la humanidad no camine coja. La universidad enseñará que todo lo que crea debe servir al hombre. Su rector, un rector, actuará de vigía, asumirá su función de timonel que guía la construcción del hombre. Esta es la gran tarea de la Universidad y del rector. La sociedad y el hombre la reclaman. Estamos preparados para ella (Rodríguez, 2003).

Con razón Iván Rodríguez capta la racionalidad de la sociedad global y los nuevos descubrimientos científicos tecnológicos, pues éstos llevan una contradicción en sí misma. Porque «los inventos del hombre honran su inteligencia. Creando nuevos mundos artificializan la vida. El confort que halaga víctima y beneficia. Da vida y quita vida. El estrés es el precio más caro que factura bienestar material a costa del vigor del espíritu» (Kapsoli, 1999).

\section{Los desafíos del futuro}

Promover nuestro propio desarrollo intelectual descolonizando el saber sigue siendo una tarea central de la peruanidad universal. Construir e institucionalizar una ciencia que democratice y unifique a la sociedad peruana desde sus actores no en un proyecto elitista de educación y universidad sino en un proyecto de educación que se vincule directamente a la solución de los problemas y desafíos del Perú-Mundo. «Preparar — decía Gerardo Ramos - a los estudiantes en la comprensión cabal de la naturaleza, de la ciencia, de la tecnología y de los productos culturales» (Ramos, 1999). Un acuerdo político democrático de los miembros de la comunidad peruana como actores sociales en interdependencia a los otros actores de la sociedad democrática global. Un modelo cuyo compromiso teórico práctico como peruanos a la vez que peruanizan y universalizan al Perú como sociedad política como un todo alejado de todo colonialismo y mesianismo.

En la universalidad de nuestro tiempo debemos apropiarnos creativamente de lo mejor de la ciencia y cultura mundial. Una universidad al servicio de la vida (Ríos, 2010) que niega toda falsa imitación, rescatar de manera creativa lo mejor de la cultura vida de los pueblos y sociedades del mundo. Hoy no podemos dejar de vivir y analizar la realidad desde su historicidad y compromiso práctico global reflexivamente con un ideal de utopía. Benedetti con razón se preguntaba: «¿Fin de las utopías? Nada más decepcionante podría anunciársele a la humanidad, cuyos avances fundamentales se han debido casi siempre a los forjadores de utopía. En mi generación latinoamericana fuimos muchos los que en distintas maneras y en diversos niveles, luchamos por utopías; y es claro, unas se cumplieron; otras, no. Al parecer, deberíamos arrepentirnos de 
esas luchas, pedir perdón por haber albergado esperanza. En lo personal, tal acto de contrición no figura en mis planes» (Benedetti, 1996).

Un nuevo paradigma civilizatorio de vida que bajo una racionalidad reflexiva de vida (Pérez y Sánchez, 1996) en un imaginario emancipatorio de vida a las personas en sociedad. Para ello la ciencia se integra superando al «intelectual específico» moderno. Integra el saber de su disciplina y campo de la ciencia inter, multi y transdisciplinariamente al saber del «mundo» bajo una filosofía transcultural de vida. Wallerstein con razón habla de la unidad de la ciencia social con todas las ciencias no como la labor de los «especialistas» sino de las comunidades cientíificas de problemática al servicio de la construcción de una cultura de vida (Wallerstein, 1997).

El nuevo desafíos de construir no un discurso global homogenizante de un falso cosmopolitismo universalista sino integrador desde las diversidades humano-naturales resolviendo los problemas globales de la vida en el planeta. Afirmar en diálogo universal el ideal de la reforma universitaria de «desarrollar nuestro propio criterio positivo para el análisis de este enfermo y yaciente que se llama «Perú». Por tanto no administrar subordinadamente el modelo asimétrico del ser, saber y poder global sino descolonizar la vida transformando democráticamente la vida. Una mentalidad liberadora donde lo mejor de la intelectualidad peruana afirma, dialoga y construye una verdadera universalización intelectual como comunidad social, científica y ética. Punto que niega toda colonización afirmando nuestro sentido de ser y saber lejos de todo "cosmopolitismo" fundamentalista o pensamiento único relativista. Solo en el cambio global ser auténticos construyendo una sociedad de vida donde negemos al civilizado y al salvaje en el espejo (Bartra, 1996).

Corresponde a las fuerzas de la peruanidad resolver nuestros problemas en la universalidad del cambio civilizatorio. Un proyecto social nacional global donde la problemática universitaria no solo se comprende verticalmente como la reforma docente, la gestión académico-administrativa y la incorporación de la Universidad al mundo académico internacional sino en una construcción social de vida de la universidad en todas sus dimensiones. Refundar la universidad reorganizando de manera profunda la economía, la estructura social, el sistema político y la cultura de nuestro país (Germaná, 2010).

Persiste la necesidad de construir una cultura nacional pero en su integración democrática transcultural global. Un paradigma de vida como proyecto de peruanidad universal de lo humano natural que se exprese realmente en un movimiento histórico cultural de vida en igualdad, libertad, solidaridad, felicidad y diferencia gestando una nueva concepción del desarrollo en el mundo global bajo el diálogo de saberes (Boaventura, 2006).

La universidad peruana del futuro se ubica en el marco de la cuarta revolución industrial científica tecnológica y el nuevo modo informacional de desarrollo. Organizarnos 
como sociedad del conocimiento acorde con nuestras identidades en integración universal de lo humano. La necesidad histórica de un proyecto nacional global que hoy no existe. En esta perspectiva el fenómeno educativo y universitario es una parte de nuestra construcción social como sociedad organizada planteando un paradigma civilizatorio y científico cultural inédito que se funda en una filosofía intracivilizatoria universal de vida y de peruanidad nacional transcultural.

Un proyecto socioeducativo global que peruaniza y universaliza al Perú como sociedad de vida y del conocimiento. Una comunidad social que descolonizada de la ideología imitativa de la modernidad y posmodernidad negativa apuesta por un modelo complejo que en diálogo constante revoluciona nuestra tradición histórica civilizatoria como encuentro solidario y libre con las otras sociedades humanas. Un paradigma socioeducativo cambiante basado en los conocimientos avanzados al servicio de la solución de los problemas esenciales del Perú-mundo.

Los ejes estratégicos de esta revolución se enmarcan en el proceso de globalización integrando la vida social en un sentido transcultural a la transformación de los espacios tiempos personales y del Estado-nación, en el contexto de la crisis terminal del sistema histórico moderno. En este curso nos corresponde orientar la vida social bajo una cultura de una «racionalidad sustantiva» de vida basada en valores y fines racionales conscientes del bien o buen vivir. Las certezas de la modernidad y premodernidad como herencia se entrecruzan con la incertidumbre, el caos y la complejidad de la vida no renunciando al ideal juvenil de la «lucha por una buena sociedad». Esa entrega total no al intelectualismo infecundo ni a la burocratización «mediocre» sino al imaginario creativo de amor a la vida que descubre la solución a los problemas en un mundo donde «la incertidumbre es maravillosa y que la certeza, si fuera real, sería la muerte moral» (Wallerstein, 2000).

La universidad del futuro organiza la vida y la cultura científica de los pueblos. Ordena sus diversidades en toda la unidad civilizatoria universal. Una tarea colectiva en sus diferentes aspectos organizacionales y programas de investigación. Si algo nos une en el futuro y el presente es construir el Perú como sociedad política. Movimiento político cultural como parte del gran movimiento cultural de los humanos por liberarse de todo dominio y explotación social. Precisamente la mayor debilidad de los universitarios peruanos es no haber sabido crear una unidad ideológica cultural en sus diferencias entre la intelectualidad y el pueblo nación diversa. Causa histórica de nuestra dependencia de los centros de poder global y del infecundo elitismo de casta o grupo. Extrañamiento que lleva a renunciar al ideal vallejiano de que «toda voz genial viene del pueblo y va hacia él» (Vallejo, 1973).

Una universidad que no se abstrae en un intelectualismo y burocratismo infecundo sino contribuye a construir una visión estratégica como tarea de elevar y elevarse como humanos. Paradigma que se opone a toda racionalidad instrumental, pues gesta día a 
día un bloque intelectual moral de humanos y peruanidad de vida. Una voluntad política consciente y práctica por alcanzar un modelo de desarrollo político de vida.

Teoría y práctica que dialoga fecundamente entre sí y con las otras identidades globales afirmando nuestra propia identidad diversa como parte inseparable de la identidad de vida. Liderazgo colectivo de la vida de nuestros pueblos gestando inéditas formas de organización política del conocimiento desde sus propios actores como universidad sociedad global.

En esta perspectiva, la investigación básica y especializada se centra en la solución de áreas estratégicas como el nuevo mundo del trabajo, la organización del conocimiento, la tecnología y la sociedad del futuro, el medio ambiente, la ciencia y tecnología punta, el control del territorio y sus recursos, la descentralización, la educación y el arte. Un nuevo sistema educativo donde la educación y la universidad no se conceptúa como la formación de ser humano mercancía sino como personas felices en sociedad. La política educativa asume una visión práctica estratégica de desarrollo humano natural socializado y sustentable.

El sistema de conocimiento integrado y especializado universitario y extrauniversitario dará origen a toda la creatividad e inventiva no de unos pocos sino de todos en un creciente y elevado nivel de intercambio socio cultural y educativo real y virtual. La «especialización» será sustituida o incorporada al trabajo transdisciplinario, multidisciplinario e interdisciplinario. La reglamentación vertical, la falta de individuación y de la sociabilidad en el aula, los planes de estudio e investigación, el sistema y tipo de gobierno, el financiamiento público, los grupos, los grados, los títulos y el nuevo papel del docente, asumirán nuevas formas y contenidos acordes con la nueva dinámica, es decir, los profundos intereses y necesidades de los peruanos de organizarse como personas en sociedad.

La tecnológica en sus diferentes medios se pondrá al servicio del estudio e investigación de las problemáticas estratégicas del Perú Mundo. La formación integral recogerá todo lo mejor de la cultura, ciencia y técnica universal. El pregrado y posgrado afirmará peruanos humanos capaces de un juicio crítico y de organizar la vida social con la previsión de la dirección y del ritmo del cambio global. El sistema del posgrado peruano conformará «el consejo peruano del futuro» a nivel nacional y regionales presentando propuesta concretas y simuladas de soluciones para el desarrollo endógeno e interdependiente de nuestra sociedad en todas sus áreas estratégicas. La universidad privada se integrará a la universidad pública como sistema universitario peruano.

Un modelo de universidad totalmente diferente al modelo individualista existente. La juventud como parte de la nación peruana asumirá el desafío con optimismo, pues su participación es la clave para su éxito. El modelo de universidad autoritaria neoliberal profundizará su creciente crisis. No elevará la calidad de vida de la sociedad peruana como un todo. El aprendizaje resolverá problemas simples y complejos aprendiendo, 
olvidando y volviendo a aprender en una relación de transitoriedad y permanencia fecundas de sociabilidad y amistad. Valorará todas las capacidades de lo humano en una formación creativa y responsable a partir de la dialéctica contradictoria de la vida. En su sistematicidad es opuesta a toda manipulación por parte de los sistemas abstractos. Un hombre socialmente individualizado con un tiempo cultural transcultural que entre el trabajo y el juego promueve el estudio como una curiosidad infinita.

Un liderazgo colectivo que propaga la nueva cultura de vida como paradigma civilizatorio. Una concepción que niega la cultura vanguardista instrumental del poder, engaño y corrupción, resolviendo los problemas en diálogo, discusión y solución colectiva y personal positiva. Una cultura organizacional que desarrolla democráticamente y de manera planificada la investigación y la enseñanza convirtiendo a la universidad en una de las instituciones unificadoras de la sociedad.

Un mundo cultural donde el individualismo da paso al intelectual orgánico que alejado de todo objetivismo y subjetivismo contribuye a la mejor calidad de vida de las sociedades. Desarrolla esquemas teórico metodológicos, modelos e hipótesis integradas, diferenciadas y comparativas rectificando incesantemente los conocimientos y las formas de organización en certidumbres de las incertidumbres del cambio social. Más que la objetividad de lo real afina constantemente sus métodos y técnicas para dar cuenta de ella y de sus soluciones. Une la ciencia directamente a las necesidades de la vida y actividad de los peruanos de todos los espacios socioculturales.

Un nuevo esquema cultural educativo que integra al nuevo paradigma de la cuarta revolución científico técnica a todos nuestros agrupamientos humanos bajo una red de redes posibilitando el desarrollo de las esferas de la comunicación, la desterritorialización, la informática, las biotecnologías, las redes y el transporte de la unidad de la ciencia, y el desarrollo de las teorías. Un modelo transcultural que pone al servicio de los humanos el conjunto de los aparatos técnicos, la industria cultural, la diversidad cultural e identidad como humanos naturaleza integrando las teorías fuertes y débiles a la nueva filosofía de una cultura de vida resolviendo la profunda crisis de individuación, socialización e identidades de la modernidad y/o posmodernidad en todo un nuevo episteme ontológico, gnoseológico, axiológico.

La universalidad del conocimiento cambia así la lógica del poder basado en la violencia y la muerte. En la cotidianidad controla, mide y orienta la vida como nunca antes regulando el propio desarrollo e interdependencia con todos los humanos unida a la naturaleza, el cosmos y todas las otras formas de vida. Una construcción consciente como política de vida. Una democracia en acción por hacer de los humanos más libres, iguales, solidarios y diferentes. Humanos que viven, sienten y comparten la vida lejos de todo fetichismo y explotación. Una nueva cultura civilizatoria que supera todo pragmatismo que al decir de Galeano hace que «El Sur aprenda geografía en mapamundis que lo reducen a la mitad de su tamaño real. Los mapamundis del futuro ¿̨lo borrarán 
del todo? Hasta ahora América Latina era la tierra del futuro. Cobarde consuelo; pero algo era. Ahora nos dicen que el futuro es el presente» (Galeno, 1996).

En síntesis, recogemos lo mejor de los aportes civilizatorios, de la propia tradición histórica de las civilizaciones reivindicando en un diálogo de saberes el mito, la utopía y la razón reflexiva de una civilización universal de vida. En este curso como parte de la diversidad universal la peruanidad cumple con la promesa de seguir construyéndose como sociedad política universal de vida y su futuro como sociedad transcultural de vida uniendo lo que la modernidad/colonialidad separó como antagonismo entre el civilizado y el bárbaro: lo verdadero, lo bueno y lo bello.

\section{Referencias}

Bauman, Z. (1999). La globalización consecuencias humanas. Buenos Aires: FCE.

BArtra, R. (1996). El salvaje en el espejo. Barcelona: Ediciones Destino S.A.

BASADRE, J. (1975). La vida y la historia. Lima: Banco Industrial.

BASADRE, J. (2010). I. Reflexiones sobre la universidad en la segunda mitad del siglo xx. En Ríos, J. La Universidad en el Perú: Historia, presente y futuro. Vol. V. La universidad en la segunda mitad del siglo XX. Lima: ANR.

Bеск, U. (1998). ¿Qué es la globalización? Falacias del globalismo, respuestas a la globalización. Barcelona: Paidós.

Benedetti, M. (1996). El capitalismo ha ganado un partido, pero no el campeonato. En Crítica de la modernidad y la globalización. Lima: Editorial Salmón.

Castells, M. (2002). Cultura y sociedad del conocimiento: presente y perspectivas de futuro. Debates culturales. Madrid: UOC.

Castells, M. (2002). La galaxia Internet, empresalsociedad. Barcelona: Plaza \& Janés.

Chávez, I. (2010). XXI. La autonomía universitaria en la legislación universitaria vigente. En Ríos, J. La Universidad en el Perú: Historia, presente y futuro. Vol. VI. La universidad en la segunda mitad del siglo XX y siglo XXI (1990-2006). Lima: ANR.

Chávez, I. (2010). Testimonio universitario sanmarquino. En Ríos, J. La Universidad en el Perú: Historia, presente y futuro. Vol. VI. La universidad en la segunda mitad del siglo XX y siglo XXI (1990-2006). Lima: ANR.

De Sousa Santos, B. (2006). Conocer desde el sur. Para una cultura politica emancipatoria. Lima: UNMSM.

Flores, V. y Mariña, A. (2000). Crítica de la globalización. Dominación y liberación de nuestro tiempo. México: FCE.

Galeano, E. (1996). La teoría del fin de la historia se pone de moda. En Crítica de la modernidad y globalización. Lima: Ediciones del Salmón. 
Garcia Canclini, N. (1999). Globalizarnos o defender la identidad. En Aproximaciones a la globalización. Venezuela: Nueva Sociedad.

Germaná, C. (2010). Los actuales retos para refundar la universidad de San Marcos. En Ríos, J. La Universidad en el Perú: Historia, presente y futuro. Vol. VI. La universidad en la segunda mitad del siglo XX y siglo XXI (1990-2006). Lima: ANR.

Haya de la Torre, V. (2009). XIV. La reforma universitaria. En Ríos, J. La Universidad en el Perú: Historia, presente y futuro. Vol. IV. La universidad en la priemra mitad del siglo XX. Lima: ANR.

Haya de la Torre, V. (1936). El antimperialismo y el APRA. Santiago de Chile: Editorial Ercilla. Ludeña, G. (1994). Reflexiones sobre el XXV Aniversario de la Universidad Ricardo Palma. En Varios: La idea de la Universidad en el Perú. Lima: URP.

MARIÁtegui, J. (1972). 7 ensayos de interpretación de la realidad peruana. Lima: Empresa Editora Amauta.

Mariátegui, J. (2009). IV. El proceso de la instrucción pública. La herencia colonial y las influencias francesa y norteamericana. En Rios, J. La Universidad en el Perú: Historia, presente y futuro. Vol. I. La universidad en la etapa colonial. Lima: ANR.

Mariátegui, J. (1973). Temas de educación. Lima: Biblioteca Amauta.

Maticorena, M. (2009). XXXIII. La universidad de San Marcos en su historia. En Ríos, J. La Universidad en el Perú: Historia, presente y futuro. Vol. II. La universidad en la etapa colonial. Lima: ANR.

Ortiz, R. (1996). Otro territorio, ensayos sobre el mundo contemporáneo. Buenos Aires: Universidad Nacional de Quilmes.

Palma, R. (2008). V. La bohemia de mi tiempo. En Ríos, J. La Universidad en el Perú: Historia, presente y futuro. Vol. III. La Universidad en el siglo XIX. Lima: ANR.

PAz, O. (1986). Tiempo Nublado, España: Biblioteca de Bolsillo.

Pérez, A. y SÁnchez, I. (1996). Complejidad y teoría social. Madrid: CIS.

Portocarrero, G. (2004). Rostros criollos del mal. Cultura y transgresión en la sociedad peruana. Lima: UPCP-UP-IEP.

Quijano, A. (1977). Dependencia, urbanización y cambio social en Latinoamérica. Lima: Mosca Azul.

Quijano, A. (1999). Coloniality and Modernity/Rationality. En Therborn, Goran y otros, Globalizations and Modernities. Stockholm: FRN.

Ramos, G. (1999). La universidad peruana en el siglo XXI. Lima: URP.

Ramos, G. (1969). Espacios históricos de la universidad peruana. En La universidad peruana en el siglo XXI, Lima: URP.

Ríos, J. (2010). I. Universidad, sociedad peruana y globalización. En Ríos, J. La Universidad en el Perú: Historia, presente y futuro. Vol. VI. La universidad en la segunda mitad del siglo XX y siglo XXI (1990-2006). Lima: ANR. 
Ríos, J. (2009). X. Sociedad, estado y universidad colonial. En Ríos, J. La Universidad en el Perú: Historia, presente y futuro. Vol. I. La universidad en la etapa colonial. Lima: ANR

Ríos, J. (2009). XII. Manifiesto de Córdova. En Ríos, J. La Universidad en el Perú: Historia, presente y futuro. Vol. IV. La universidad en la priemra mitad del siglo XX. Lima: ANR

Ríos, J. (2008). VII. Sociedad y universidad en el siglo XIX. En Ríos, J. La Universidad en el Perú: Historia, presente y futuro. Vol. III. La universidad en el siglo XIX. Lima: ANR.

Ríos, J. (2000). Globalización y crisis de paradigma. Hacia una teoría transcultural de la sociedad humana, en Filosofía Globalización y multiculturalidad. Vol. I. Actas del VIII Congreso Nacional de Filosofía. Lima: UNMSM.

Ríos, J. (1998). Actores y estructuras sociales en la globalización. En Revista de Sociología. Vol.X. Lima: UNMSM.

Rodríguez, I. (2010). III. Testimonio universitario sanmarquino. En Ríos, J. La Universidad en el Perú: Historia, presente y futuro. Vol. VII. La universidad en la segunda mitad del siglo XX y siglo XXI (Vida universitaria, cátedras y bografias). Lima: ANR.

Rodríguez, I. (2009). Pensadores y forjadores de la universidad en el Perú. Lima: ANR.

Rodríguez, I. (2003). Otra ventana sobre Ricardo Palma. Lima: URP Editorial Universitaria.

Rodríguez, I. (2003). XXII. La autonomía universitaria en la legislación universitaria vigente. Hacia una nueva universidad en el Perú. En García Zárate. O. (compilador). Lima: Fondo Editorial UNMSM.

Sánchez, L. (2009). La universidad en Latinoamérica. En Ríos, J. La Universidad en el Perú: Historia, presente y futuro. Vol. IV. La universidad en la primera mitad del siglo XX. Lima: ANR.

SÁNCHez, L. (1968). Balance y liquidación del novecientos ¿Tuvimos maestros en nuestra América? Lima: UNMSM.

Stiglitz, J. (2002). El malestar de la globalización. España: Taurus.

SEN, A. (2000). Desarrollo y libertad. Barcelona: Planeta.

Touraine, A. (1998). ¿Qué es el desarrollo? Lima: PUCP.

VAlCÁRCEL, L. (1981). Memorias. Lima: IEP.

Vallejo, C. (1973). Arte y revolución. Lima: Mosca Azul Editores.

Wallerstein, I. (1997). Conferencia Forum 2000: Inquietudes y esperanzas en el umbral del nuevo milenio. Praga: Iniciativa Socialista.

Wallerstein, I. (1996). The Age of Transition: Trajectory of the World-System, 1945-2025. Londres: Zed Press.

Wallerstein, I. (1997). Abrir las ciencias sociales. México: Siglo XXI. 